\title{
ASPECTOS SOCIOECONÔMICOS DO MUNICÍPIO DE BOTUPORÃ - BAHIA E SUA INSERÇÃO NO CONTEXTO DO DESENVOLVIMENTO BAIANO
}

\section{Socioeconomic aspects of the city of Botuporã - Bahia and its insertion in the context of Bahia development}

Aspectos socioeconómicos del municipio de Botuporã - Bahía y su inserción en el contexto del desarrollo bahiano

Vanessa Vieira Souza ${ }^{1}$ https://orcid.org/0000-0002-9015-8826 Miriam Cléa Coelho Almeida ${ }^{2}$ https://orcid.org/0000-0002-2662-4466

\footnotetext{
${ }^{1}$ Graduada em Geografia pela Universidade Estadual do Sudoete da Bahia - UESB, Brasil, email - vanessa_vieira04@hotmail.com.

${ }^{2}$ Pós Doutoranda pela Universidade Federal de Sergipe- UFS-Brasil, Professor(a) Doutora - Adjunto do Departamento de Gografia da Universidade Estadual do Sudoete da Bahia - UESB, Brasil, email - miriamclea@gmail.com
}

\section{Resumo}

O presente artigo, objetiva analisar a inserção de Botuporã no contexto do desenvolvimento econômico baiano. Para tanto, faz-se, brevemente, uma discussão teórica sobre o desenvolvimento desigual e combinado do espaço, para compreender o papel das consideradas "pequenas" cidades e, mais incipienteespecificamente, desse município no processo geral da acumulação capitalista. A cidade de Botuporã localizada no território de identidade da Bacia do Paramirim possui uma agricultura que se baseia na policultura de milho, feijão e mandioca e na criação de bovinos e aves, uma atividade comercial incipiente, e um setor de serviços que tem na Prefeitura Municipal o seu principal promotor. Entretanto, estas condições, aliadas às estratégias gerais do desenvolvimento desigual e combinado do espaço, não exclui o município do contexto geral do desenvolvimento baiano.

Palavras-chave: Desenvolvimento desigual e combinado. Ecomonia. Cidades.

\begin{abstract}
This article aims to analyze the insertion of Botuporã in the context of Bahian economic development. For this, a theoretical discussion about the uneven and combined development of space is made, to understand the role of "small" cities and, more specifically, of that municipality in the general process of capitalist accumulation. The city of Botuporã located in the territory of identity of the Basin of the Paramirim basin
\end{abstract}


has an agriculture that is based on the polycuture of corn, beans and cassava and on the breeding of cattle and birds an insipient commercial activity and a service sector that has in the City Hall its main promoter. However, these conditions, combined with the general strategies of the unequal and combined development of space, do not exclude the municipality from the general context of Bahian development

Keywords: Uneven and combined development. Ecomony. Cities.

\section{Resumen}

El presente artículo, objetiva analizar la inserción de Botuporã en el contexto del desarrollo económico bahiano. Para ello, se hace, brevemente, una discusión teórica sobre el desarrollo desigual y combinado del espacio, para comprender el papel de las consideradas "pequenas" ciudades y, más específicamente, de ese municipio en el proceso general de la acumulación capitalista. La ciudad de Botuporã ubicada en el territorio de identidad de la Cuenca del Paramirim posee una agricultura que se basa en la policultura de maíz, frijoles y mandioca y en la cría de bovinos y aves, una actividad comercial incipiente, y un sector de servicios que tiene en el Ayuntamiento Municipal su principal promotor. Sin embargo, estas condiciones aliadas a las estrategias generales del desarrollo desigual y combinado del espacio, no excluye el municipio del contexto general del desarrollo bahiano.

Palabras clave: Desarrollo desigual y combinado. Ecomonia. Ciudades

\section{Introdução}

O presente artigo analisa a inserção de Botuporã no contexto geral do desenvolvimento econômico baiano. A cidade de Botuporã localizada no território de identidade da Bacia do Paramirim possui uma população com pouco mais de onze mil habitantes, a maior parte reside no meio rural, apesar do crescimento da área urbana. A área urbana botuporãense se formou no entorno da Fazenda Caititu. Com o desenvolvimento gradativo passou a ser distrito denominado Monte Belo e depois este distrito foi emancipado para a formação do município de Botuporã-BA. Esse município tem uma agricultura que se baseia na policultura, sobretudo, de milho, feijão e mandioca, e na criação de bovinos e aves. A atividade comercial e de serviços é incipiente e tem, em grande medida, a família ocupando os empregos. Nessas condições, a Prefeitura Municipal é a principal responsável pela geração de emprego e renda.

Dessa maneira, diante da falta de perspectiva de emprego, a população fica refém dos empregos gerados pela Prefeitura e do pagamento de aposentadorias e 
pensões. Atualmente, Botuporã dispõe de serviços que atendem as necessidades básicas e mais urgentes da população. Além disso, sofre com a forte concorrência de cidades vizinhas, que se tornam mais atrativas para a população consumidora e se apresentam como mais uma ameaça para o desenvolvimento econômico de Botuporã.

A análise do desenvolvimento deste município no contexto baiano permitiu um levantamento e uma sistematização de dados fundamentais para compreender a sua participação no desenvolvimento desigual e combinado do espaço baiano e a forma com que o município participa desse processo. Além disso, reforçou a necessidade de se pensar a produção das cidades articulada com a divisão territorial do trabalho e com a relação contraditória capital-trabalho.

\section{O desenvolvimento desigual e combinado e a produção do espaço urbano na Bahia}

Para se compreender a inserção da cidade de Botuporã no processo de produção do espaço urbano baiano é fundamental considerar a lógica capitalista que orienta esta produção. Desse modo, parte-se do princípio de que a produção capitalista tem como seu maior objetivo acumular riquezas e, para isso, não importa que um lastro de desigualdade perfile o seu caminho. Aliás é dessa lógica que, em parte, resulta a tese do desenvolvimento desigual e combinado do espaço. Desta forma, o capital está em um constante vaivém, para ajustar as suas necessidades de sempre obter lucro. Por isso, o capital se mobiliza para onde há a possibilidade de ampliar a taxa de lucro. Assim, o capital permanece em um movimento constante, aproveitando todas as oportunidades, por meio de um desenvolvimento estrategicamente combinado e contraditório como ensina Smith (1988, p.213): “Isso fica muito claro na contradição geográfica entre desenvolvimento e subdesenvolvimento, em que a superacumulação em um polo corresponde a superacumulação de trabalho no outro"

Esse processo de produção diferencial do espaço, em que uns beneficiam mais do que outros no modo de produção capitalista, acentuou-se principalmente após o desenvolvimento dos meios tecnológicos e de serviços. Como avalia Harvey:

[...] desenvolvimento geográfico desigual, no interior do qual regiões ricas tendem a ficar mais ricas, enquanto regiões pobre tendem a ficar mais pobres. Regiões avançadas atraem atividades pela vitalidade de seus mercados, pela força de sua infraestrutura física e social e pela facilidade com que proporcionamos mão de obra e meios necessários 
para a produção. Dispõem de recursos (na forma de uma base tributária), o que atrai mais trabalho e capital. Rotas de transporte centradas na região são criadas porque é ali que está o tráfego. Como consequência, mais capital é atraído. Em compensação, outras regiões carecem de serviços ou perdem cada vez mais atividades. Elas entram numa espiral descendente de depressão e decadência. $\mathrm{O}$ resultado são concentrações regionais desiguais de riqueza, poder e influência (HARVEY, 2016, p.142).

Essas formulações presentes em Harvey (2016) lançam luzes para explicar a concentração de capital nos mais diversos e diferentes lugares tendo como princípio motor a sua articulação com a lei do desenvolvimento desigual e combinado. Um exemplo disso é quando o capital chega a um ponto de saturação em um determinado lugar, ele necessariamente, procura outros espaços para a sua reprodução.

O que aconteceu após a década de 1990 com as cidades consideradas "médias" que passaram a receber um maior contingente populacional e também começaram a receber indústrias de forma mais intensa, ilustra bem esse processo de "ajuste espacial" da acumulação capitalista, tão bem demonstrado em Harvey (2005). Esse processo realizou-se de modo articulado com o Estado que criou as condições como aos incentivos fiscais oferecidos às empresas, dentre outras medidas.

Porém, esse processo de "ajuste" ou de "deslocalização" das atividades econômicas como conclui Harvey (2005) é controlado e articulado pelo capital internacional, em que a direção da empresa permanece na matriz no país de origem e a produção de consumo para as empresas filiais, desta maneira o capital produz os espaços da forma que melhor convém como: criando espaços globais (grandes metrópoles), espaços centrais ("cidades médias") e cidades de reserva de força de trabalho ("pequenas cidades"). Por essa razão, Smith (1988, p.19) adverte que o desenvolvimento desigual e combinado “[...] ocorre em várias escalas espaciais", embora sejam pouco examinado em escalas menores.

No século XIX, com base nos estudos de Carlos (1992, 2001), com a produção do espaço urbano cumpri o papel de viabilizar as trocas de produtos originados das atividades agrícolas. Após esse período a cidade é reconhecida como o lócus da produção, circulação, distribuição e consumo de bens e serviços, sobretudo, originados da atividade industrial. Desde a intensificação das atividades industriais, examinada por Lefèbvre (2001) e das produções comerciais e de serviços na atualidade, a produção de cidades esteve cada vez mais comprometidas com os interesses da realização da 
acumulação capitalista, que exigiu cidades cada vez maiores e mais estruturadas, tanto internamente quanto externamente. As cidades metropolitanas ilustram bem esse processo de expansão e complexificação do espaço urbano. No entanto, autores como Benko (1999) e Harvey (2004), entre outros observam um processo recente de desconcentração das atividades econômicas, industriais, comerciais e de serviços para outras cidades que, até então, não participavam diretamente dessa concentração.

Com a desconcentração das atividades econômicas nota-se que, embora ocorra um refoço das cidades que já se mostravam importantes na escala regional ou subregional, isso não impediu que cidades pouco expressivas do ponto de vista econômico fossem também inseridas nesse processo, sobretudo, com as atividades relacionadas ao agronegócio mundial. Essa característica torna ainda mais complexa a tarefa de entender o desenvolvimento das cidades e mostra que as formas tradicionais de classificação ou tipificação não são suficientes para compreedê-las.

O tamanho da malha urbana e os dados populacionais são importantes, porém não dão conta de explicar a realidade das cidades e a importância econômica que possuem para o capital. Desse modo, uma cidade considerada pequena pode possuir um forte desenvolvimento econômico por abrigar importantes atividades agrícolas ligadas ao agronecócio mundial e outras que, como já apontado em Harvey (2016) se encontram numa "espiral descendente de depressão e decadência".

Ao se considerar os dados demográficos e econômicos das cidades baianas, disponibilizados pelo Instituto Brasileiro de Georafia e Estatística (IBGE) - 2010 e Superintendência de Estudos Econômicos e Sociais da Bahia (SEI) - 2016, na Bahia, apesar de se registrar uma predominância de cidades que se encontram nas condições de depressão e decadência, existem aquelas "pequenas grandes", cujas características econômicas as relacionam ao agronegócio mundial com a produção de commoditees agrícolas a exemplo de cidades localizadas na Chapada Diamantina, no Oeste baiano ${ }^{3}$, entre outras. E ainda, as cidades que ampliaram seus contingentes populacionais, suas atividades econômicas, mas também seus problemas socioterritoriais.

Vê-se que essa tendência de descentralização aliada ao avanço do aparato técnico científico tem, aos poucos, diminuído a dependência das cidades interioranas em

\footnotetext{
${ }^{3}$ Maiores informações sobre as cidades do Oeste da Bahia e sua vinculação com o agronegócio podem ser encontradas na publicação da SEI - 2017, intitulada: "Cidades do agronegócio no oeste baiano". Disponível em: hhtpps://www.sei.ba.gov.br/imagis/publicacoes/download/textos_discussao/texto_ discussao_13.pdf 
relação ao centro principal: a capital Salvador e sua região metropolitana que, historicamente, manteve uma grande distância do desenvolvimento das demais regiões da Bahia. Importantes pesquisadores que estudaram sobre o processo de urbanização baiano classificaram, esse desenvolvimento desigual como "macrocefalia baiana", a exemplo de Santos (1993), Silva, Silva e Silva (2014), dentre outros. Embora ainda hoje, Salvador e sua região metropolitana permaneçam como a maior produtora de serviços, empregos e produtos.

Botuporã figura entre as cidades da Bahia que apresentam poucas inovações, tendo apenas a capacidade de suprir o município com ofertas básicas de serviços e produtos. Ou seja, mesmo com o crescimento da urbanização na Bahia, muitas cidades exercem uma forte relação com o meio rural, prevalecendo ainda à agricultura familiar como fonte de renda para a população.

Apesar disso, não se pode dizer que esses espaços não estejam conectados ao processo geral da acumulação capitalista, vez que na interpretação de Smith,

\begin{abstract}
Em sua tendência constante para acumular quantidades cada vez maiores de riqueza social sob o seu controle, o capital transforma a face do mundo inteiro. Nenhuma pedra feita por Deus permanece no lugar, nenhuma relação original com a natureza permanece inalterada, nenhum ser vivo deixa de ser afetado. Em consequência, os problemas da natureza, do espaço e do desenvolvimento desigual são colocados juntos pelo próprio capital. O desenvolvimento desigual é o processo e o padrão concreto da produção da natureza que, de alguma maneira, se reduz à discussão do valor de uso, do valor, e do valor de troca (SMITH, 1988, p. 20).
\end{abstract}

Nessa perspectiva, o município de Botuporã, apesar de compor o quadro dos municípios que constituem a "periferia" das regiões desenvolvidas, não pode ser compreendido como um espaço "excluído" do desenvolvimento, na medida em que dele participa mesmo na condição de "periferia" fornecedora de produtos agrícolas ou como reserva de força de trabalho. Daí Smith $(1988$, p.16) conclui que o desenvolvimento desigual e combinado "[...] é a expressão geográfica sistemática das contradições inerentes à própria construção e estrutura do capital".

\title{
As atividades econômicas e as relações intermunicipais e inter-regionais de
}

\section{Botuporã.}


Para analisar as articulações intermunicipais e inter-regionais de Botuporã é importante fazer um balanço para se conhecer as atividades existentes e inexistentes que, em grande medida, contribuem para viabilizar essas relações. Além disso, verificar a posição do município de Botuporã em relação à situação econômica entre as cidades circunvizinhas.

Atualmente, Botuporã dispõe de serviços que atendem as necessidades mais urgentes da população tais como: agência rodoviária, bancos, correios, caixa lotérica, farmácias, clínicas odontológicas (públicas e privadas), serviço de saúde (públicos e privados), escolas (públicas e privadas), assistência social e conselho tutelar. Na área do lazer: clube privado e quadras poliesportivas. O comércio dispõe de postos de gasolina, lanchonetes, pizzarias, comércios de cereais, loja de roupas e sapatos, padarias, academias, entre outros.

Com a observação dos dados da Tabela 1 é possível analisar o desenvolvimento dos setores de atividades econômicas no município definidos pela (SEI).

Tabela 1 - Relações do Mercado de Trabalho Formal em Botuporã-BA, 2010 e 2014.

\begin{tabular}{|c|c|c|c|c|}
\hline \multirow[t]{2}{*}{ Setor de Atividade } & \multicolumn{3}{|c|}{2010} & 2014 \\
\hline & Estabelecimentos & $\begin{array}{l}\text { Estoque } \\
\text { de } \\
\text { emprego } \\
\text { formal }\end{array}$ & Estabelecimentos & $\begin{array}{l}\text { Estoque de } \\
\text { emprego } \\
\text { formal }\end{array}$ \\
\hline Extrativa Mineral & 0 & 0 & 0 & 0 \\
\hline Indústria de Transformação & 2 & 3 & 8 & 15 \\
\hline $\begin{array}{l}\text { Serviços industriais de } \\
\text { utilidade pública }\end{array}$ & 0 & 0 & 0 & 0 \\
\hline Construção civil & 2 & 15 & 4 & 24 \\
\hline Comércio & 26 & 42 & 28 & 45 \\
\hline Serviço & 6 & 39 & 13 & 56 \\
\hline Administração pública & 1 & 278 & 1 & 279 \\
\hline $\begin{array}{l}\text { Agropecuária, extração } \\
\text { vegetal, caça e pesca }\end{array}$ & 1 & 2 & 1 & 1 \\
\hline Total & 38 & 379 & 55 & 420 \\
\hline
\end{tabular}

Fonte: MTE-Caged/MTE-RAIS. SEI (2016). Organização Vanessa Souza.

Um dos setores de atividades que cresceu foi o setor da indústria, tendo dois estabelecimentos em 2010, e oito estabelecimentos em 2014. Porém, ainda é um número pouco expressivo, especialmente por se tratar de indústria de pequeno porte. O comércio 
da cidade apresenta um pequeno acréscimo, tanto em estabelecimentos quanto na geração de empregos. Mas, se comparado com os demais setores, chama atenção o crescimento dos serviços que cresceu pouco mais do dobro. Talvez, uma das razões para esse crescimento seja a modernização da agricultura que gerou emprego e renda e a população procurou mais os serviços, sobretudo, na área de saúde como: clínicas de odontologia, academias com equipamentos e técnicas específicas.

Contudo, os dados confirmam a grande dependência da população da geração de emprego e renda pela Prefeitura Municipal. Esse quadro possui desdobramentos políticos importantes e têm gerado conflitos e tensões, pois as vagas são, quase sempre, preenchidas por apadrinhamentos políticos, ficando aqueles da oposição excluídos. Lamentavelmente, a falta de concurso público só aumenta essa dependência e pressão.

A construção civil foi um dos setores que também apresentou um avanço na geração de emprego formal, o que contribui para a permanência da força de trabalho na localidade. Já o setor de agricultura, referente à extração vegetal caça e pesca, houve um decréscimo na geração de emprego, com dois funcionários registrados em 2010, e apenas um funcionário registrado em 2014. Porém, a agricultura e a pecuária tem uma produção proporcional à cidade, como mostram as Tabelas 2 e 3.

Tabela 2 - Cultivos agrícolas no Município de Botuporã-BA, 2016.

\begin{tabular}{c|c}
\hline Cultura & Quantidade (tonelada) \\
\hline Arroz & 36 \\
\hline Banana & 64 \\
\hline Coco-da-baía & 45 \\
\hline Feijão & 180 \\
\hline Mandioca & 150 \\
\hline Milho & 1200 \\
\hline
\end{tabular}

Fonte: SEI (2016). Organização Vanessa Souza.

Assim, existe produção satisfatória para o consumo local por meio dessas atividades agropecuárias. Registra-se um grande número de efetivos de animais, principalmente, frangos com 22.950 cabeças e Bovinos com 15.972 cabeças. Na produção de cultivos agrícolas destaca-se a produção de milho com 1.200 toneladas no ano de 2016. Porém, a força de trabalho empregada nesse setor é, quase que exclusivamente, informal, familiar e temporária com garantia de trabalho somente durante o tempo de plantação e colheita, estando sujeitos a outros tipos de trabalho quando fora desse período, por não serem trabalhadores formais. 
Tabela 03 - Efetivos de animais no município de Botuporã-BA, 2016.

\begin{tabular}{l|l}
\hline Animais & Quantidade (cabeça) \\
\hline Bovinos & 15.972 \\
\hline Caprinos & 815 \\
\hline Equinos & 1.375 \\
\hline Galinhas & 8.195 \\
\hline Galos, Frangos e Pintos & 22.950 \\
\hline Ovinos & 1.635 \\
\hline Suínos & 5.800 \\
\hline Fonte: SEI (2016). Organizac̃̃o Vanesa Souza
\end{tabular}

Fonte: SEI (2016). Organização Vanessa Souza.

Já o extrativismo mineral é uma atividade inexistente no município como pode ser visto nos dados da SEI (2016) em que não se registra nenhum estabelecimento nos anos de 2010 e 2014. Dessa forma, não apresenta disponibilidade de recursos minerais de alto valor econômico, tais como: minerais fósseis (carvão, petróleo), minerais não fósseis (ouro, prata). Registra-se apenas uma extração de material não metálico como a areia, para o uso na construção civil.

Os serviços industriais de utilidade pública, também não apresentam estabelecimentos nos anos de 2010 e 2014 - SEI (2016), ou seja, o município têm somente indústrias de caráter privado, sem a presença de indústrias que possa produzir para fins públicos.

Ainda assim, com a diminuição de empregos formais em alguns setores, e acréscimo em outros, o município de Botuporã, teve um ganho de 4\% em 2004, com 1.164 postos de estoque de trabalhadores e em 2014 com 1.210 (MTE-Caged/MTE-RAIS. SEI - 2016) ${ }^{4}$.

Esse panorama geral das atividades econômicas faz crer que Botuporã não se apresenta como um local para a busca da satisfação das necessidades da população de seu entorno. Com isso, pode-se inferir que as relações deste município com os demais municípios circunvizinhos se dão muito mais pelas necessidades que os botuporãenses têm em buscar satisfazer suas necessidades em outros lugares.

Assim, as cidades de Paramirim, Guanambi e, principalmente, Tanque Novo, mantêm relações com Botuporã, pois, a pesquisa de campo (junho/2018) revelou que as mesmas são procuradas pela população botuporãense, para a satisfação das necessidades

\footnotetext{
${ }^{4}$ Indicador de variação de emprego utilizado MTE-Caged/MTE-RAIS. 
ligadas aos ramos comerciais de eletrônicos, eletrodomésticos, roupas, calçados, e variedades para decoração de festas. Este comportamento demonstra uma carência em certos ramos comerciais na cidade ou, até mesmo, pouca oferta de preços acessíveis para a população, que por consequência procura as cidades vizinhas para fazer compras.

Esta saída da população para outros municípios contribui para uma baixa dinâmica comercial na cidade de Botuporã e para o fechamento de algumas lojas, conforme relatos de moradores e comerciantes entrevistados durante a pesquisa de campo (2018). O movimento inverso da população de cidades circunvizinhas consumirem na cidade de Botuporã é pouco expressivo como indicam os comerciantes locais. Nestas condições, e considerando que a saída da população está fortemente relacionada a busca de emprego que garanta a sobrevivência, como evidenciados pelos depoimentos dos moradores na pesquisa de campo (2018), é possível crer que esta cidade desempenha um papel importante no processo geral da acumulação capitalista como lugar, ou para lembrar Perpétua (2013), como "célula espacial" de reserva de força de trabalho.

Retomando a questão das relações comerciais, o Gráfico 1 evidencia por meio da opinião dos comerciantes, a concorrência que enfrentam com outros municípios.

Gráfico 1 - Opinião dos empresários locais com relação a concorrência com outros municípios. Botuporã-BA, 2018

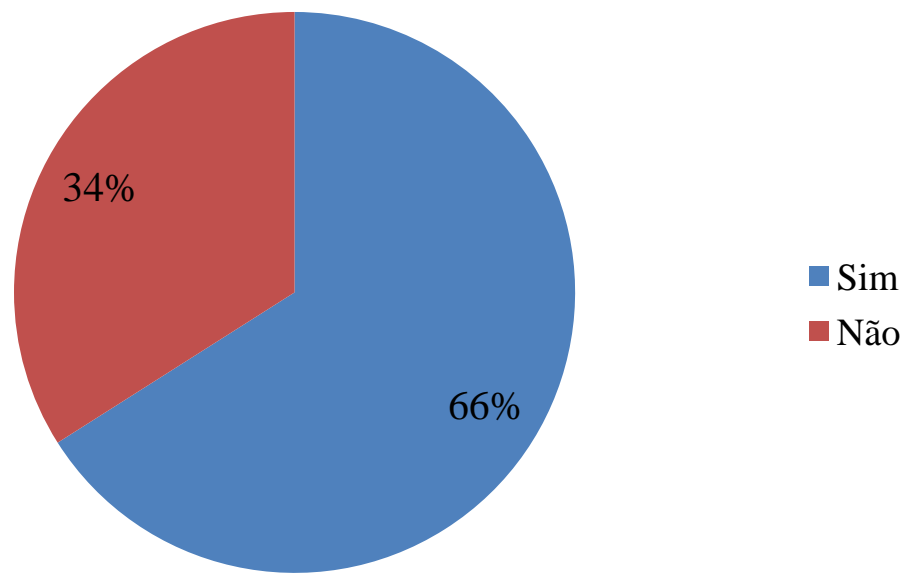

Fonte: Trabalho de campo, (2018).

Os comerciantes da cidade de Botuporã alegam existir uma grande concorrência das cidades vizinhas como demonstra os dados do Gráfico 1, com 66\%, que responderam existir uma forte influência comercial das cidades no entorno. E os outros $34 \%$ dos comerciantes afirmam não existir uma concorrência comercial. Em geral, esses 
comerciantes são do ramo de produtos de consumo diário como o comércio de cereais, padarias, entre outros, em que a população faz uso frequente, sem muita necessidade de locomoção para outras cidades.

Esta realidade local reforça o entendimento de que a produção das cidades e do urbano precisa ser analisada à luz da relação contraditória capital-trabalho. Um reforço a esta compreensão está presente em Santos (2010), em seu texto "A natureza contraditória da urbanização em um contexto de maior complexidade na produção das cidades baianas", ao concluir: “[...] a discussão sobre a relação capital- trabalho passa a ser o cerne da análise da problemática urbana porque abre novas perspectivas para o debate sobre a construção de um outro urbano e de uma outra urbanização" (SANTOS, 2010, p.74).

\section{Considerações Finais}

Pelo exposto, observa-se que as diferenças de desenvolvimento no espaço baiano, sobretudo, urbano, são a expressão das contradições inerentes ao processo de acumulação capitalista. Esse entendimento permite compreender que as cidades, a exemplo de Botuporã, mesmo apresentando um nível de desenvolvimento menor que outras regiões, ou se constituindo em espaços "periféricos", ainda assim, se inserem na dinâmica do desenvolvimento baiano, sobretudo com a disponibilização da força de trabalho.

Esta constatação reafirma a necessidade de se levar em consideração a relação contraditória capital-trabalho na análise da produção das cidades, de modo a superar as limitações teóricas e práticas presente nas classificações e tipificações tradicionais das cidades.

Com uma base econômica frágil, com pouca oferta de emprego e renda e perdendo na concorrência comercial para outras cidades circunvizinhas, a população botuporãense torna-se refém dos poucos empregos gerados pela Prefeitura e comércio local. Assim, para muitos trabalhadores resta a venda de sua força de trabalho em outro lugar, como estratégia de sobrevivência.

A realidade empírica analisada corrobora a tese do desenvolvimeto desigual e combinado em que as desigualdades que, historicamente, marcaram a produção do espaço urbano na Bahia não resultam do acaso, mas foram, estrategicamente, 
formuladas para atenderem aos interesses da acumulação capitalista em diferentes contextos históricos. Nesta perspectiva analítica, compreende-se ser acertada a preocupação em considerar a natureza contraditória do processo de produção das cidades que deriva da divisão territorial do trabalho e como dita, da relação conflituosa capital-trabalho.

\section{Referências}

BAHIA. Superintendência de Estudos Econômicos e Sociais da BAHIA - SEI. Setores de atividades. Disponível em < http://www.sei.ba.gov.br/site/resumos/indicadores/ indicadores_2904209.pdf $>2016$.

BAHIA. Superintendência de Estudos Econômicos e Sociais da BAHIA - SEI. Setores de atividades. Disponível em < https://www.sei.ba.gov.br/imagis/publicacoes/download/ textos_discussao/texto_discussao_13.pdf $>2017$.

BAHIA. Superintendência de Estudos Econômicos e Sociais da BAHIA - SEI. Cidades do agronegócio no oeste baiano Disponível em hhtpps://www.sei.ba.gov.br/imagis/ publicacoes/download/textos_discussao/texto_discussao_13.pdf

BENKO, Georges. Economia espaço e globalização: Na aurora do século XXI. São Paulo: Hucitec, 1999. Tradução: Antonio de Pádua Danesi.

BRASIL. Instituto Brasileiro de Geografia e Estatística - IBGE. Censos Demográficos. Disponível em < https://cidades.ibge.gov.br/brasil/ba/botupora $>2010$.

BRASIL. Cadastro Geral de Empregados e Desempregados - CAGED. Relação Anual de Informações Sociais - RAIS. Disponível em < https://www.sei.ba.gov.br/index.php? option=com_content \&view=article\&id=651\&Itemid=355 $>$ Acesso em Junho de 2018.

CARLOS, Ana Fani Alessandri. A cidade: $O$ homem e a cidade. A cidade e o cidadão de quem é o solo urbano. São Paulo: Contexto, 1992.

CARLOS, Ana Fani Alessandri. Espaço-tempo na metrópole: A fragmentação da vida cotidiana. São Paulo: Contexto, 2001.

HARVEY, David. Novo Imperialismo. São Paulo: Loyola, 2004

. A Produção Capitalista do Espaço. São Paulo: Annablume, 2005.

17 Contradições e o fím do capitalismo. São Paulo: Boitempo, 2016.

LEFÈBVRE, Henri. O Direito a cidade. São Paulo: Centauro, 2001. Tradução: Rubens Eduardo Frias.

PERPETUA, Guilherme Marini. Mobilidade espacial do capital e da força de trabalho: elementos para uma teorização geográfica a partir da matriz marxista. Pegada, Presidente Prudente, vol. 14, nº1, julho 2013. 
SANTOS, Jânio. A natureza contraditória da urbanização em um contexto de maior complexidade na produção das cidades baianas In: LOPES, Diva Maria Ferlin, HENRIQUE, Wendel. (Org). Cidades Médias e Pequenas: Teorias, Conceitos e Estudo de Casos. Salvador: SEI, 2010.

SANTOS, Milton. A urbanização brasileira. São Paulo: Edusp, 1993.

SILVA, Sylvio Bandeira de Mello; SILVA, Bárbara Christine Nentwing; SILVA, Maina Pirajá. A região metropolitana de Salvador na rede urbana brasileira e sua configuração interna. Scripta Nova, Barcelona, V. 18 n 479, 10 de junho de 2014.

SMITH, Neil. Uma Teoria Oscilatória do Desenvolvimento Desigual. Rio de Janeiro: Bertrand Brasil, 1988. 